COORDINADORES DE LOS DEPARTAMENTOS ACADÉMICOS

D.A. de Ciencias Dinámicas

Dr. Manuel Palomino Yamamoto

D.A. de Ciencias Morfológicas

Dr. Emiliano Salas Reyes

D.A. de Cirugía

Dr. Luis Izquierdo Vásquez

D.A. de Enfermería

Lic. Juana Durand Barreto

D.A. de Medicina Humana

Dr. Washington Rodríguez Gutiérrez

D.A. de Medicina Preventiva y Salud Pública

Dr. Jorge Alarcón Villaverde

D.A. de Microbiología Médica

Dr. Luis Solano Mendoza

D.A. de Obstetricia y Ginecología

Dr. Alejandro Barreda Gallegos

D.A. de Patología

Dr. Hernán Velarde Núñez

D.A. de Pediatría

Dr. Antonio Meza-Cuadra Velásquez

D.A. de Psiquiatría

Dr. Alejandro Barturén Dávila

D.A. de Tecnología Médica

Dr. Celso Huamán Correa

DIRECTORES DE LAS ESCUELAS ACADÉMICO

PROFESIONALES

E.A.P. de Enfermería

Lic. Tula Espinoza Moreno

E.A.P. de Medicina Humana

Dr. Eric Bravo Basaldúa

E.A.P. de Nutrición

Lic. Rosa Bardales Hoyos

E.A.P. de Obstetricia

Lic. Clara Rojas Espinoza

E.A.P. de Tecnología Médica

Lic. Nora Acosta Rengifo

DIRECTORES DE LOS INSTITUTOS Y

CENTROS DE INVESTIGACIÓN

Biología Andina

Dra. Elydia Mujica Albán

Bioquímica y Nutrición “Alberto Guzmán Barrón”

Dra. Acela Inés Arnao Salas

Investigaciones Clínicas

Dr. Sergio Ronceros Medrano

Medicina Tropical "Daniel A. Carrión"

Dr. Abelardo Tejada Valencia

Patología

Dr. Felio Palomino Paz

Ética

Dr. Pedro Ortiz Cabanillas

DIRECTORA DEL CENTRO DE EXTENSIÓN

UNIVERSITARIA Y PROYECCIÓN SOCIAL

Dra. Gloria Larrabure Torrealva

DIRECTOR DE LA UNIDAD DE INVESTIGACIÓN Dr. Sergio Ronceros Medrano

Anales de la Facultad de Medicina es una publicación oficial de la Facultad de Medicina-UNMSM, destinada a la difusión de asuntos de educación, investigación y temas relacionados a la práctica médica, a la enseñanza universitaria y al mejoramiento de la Salud Pública. El primer número apareció en Enero de 1918, siendo Decano el Dr. Ernesto Odriozola y su primer Secretario de Redacción el Dr. Hermilio Valdizán. Los Anales de la Facultad de Medicina de San Fernando acepta la solicitud de publicación de artículos que sean nacionales o extranjeros originales e inéditos.

Ninguna parte de esta publicación puede ser reproducida, transmitida en ninguna forma o medio alguno, electrónico o mecánico, incluyendo las fotocopias, grabaciones o cualquier sistema de recuperación de almacenaje de información, sin la autorización por escrito del Comité Editorial.

Copyright $@ 2005$, Facultad de Medicina-UNMSM.

Depósito Legal de acuerdo al artículo 23 D.S. Nº17-98 ED de la Ley de Depósito Legal vigente: Nº 150198-2968.

Esta publicación cuenta con el apoyo del Consejo Superior de Investigaciones, UNMSM.

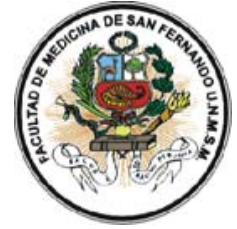

\section{Anales de la Facultad de Medicina}

UNIVERSIDAD NACIONAL MAYOR DE SAN MARCOS

El presente número de Anales publica dos investigaciones que se refieren a problemas importantes en la mujer peruana: el cáncer de mama y el cáncer de cérvix. La prevalencia del cáncer de mama aumenta en el país; en la capital de la República es el cáncer más frecuente en la mujer y ello obliga a que se busque nuevas maneras técnicas de detección y de pronóstico. Se ha determinado que la amplificación y sobreexpresión del factor de crecimiento epidérmico humano tipo 2 (HER-2) en el carcinoma de mama están asociadas a un curso clínico adverso, un menor tiempo de sobrevida libre de enfermedad y de sobrevida total; pero, también, de una mejor respuesta al tratamiento con el anticuerpo específico contra el HER-2. La investigación que se publica encontró que la sobreexpresión 3+ de HER-2 se asoció al tipo histológico ductal infiltrante no especificado, a la presencia de enfermedad de Paget de pezón y a la ausencia de expresión de receptores de estrógenos, resultados algo diferentes a otros estudios nacionales y foráneos.

El cáncer de cuello uterino es el cáncer más frecuente en la mujer peruana. En el estudio que publica Anales, en casos de citología Papanicolaou atípica sospechosa, la biopsia determinó que las lesiones escamosas intraepiteliales y el carcinoma cervical tuvieron alta prevalencia en el grupo poblacional estudiado. La biopsia dirigida del cérvix, bajo control colposcópico, perfecciona los resultados de la citología, aún si ella ha sido realizada por un patólogo experto. Una vez hecho el diagnóstico, las lesiones deben ser tratadas en un centro especializado en neoplasias.

En el Perú existe falta de donantes para transplante de órganos. Una opción inédita en nuestro medio para receptores añosos consiste en el trasplante de ambos riñones de donante añoso en un mismo receptor, dando importancia a la histología renal de biopsia en cuña por congelación como método seleccionador. El resultado de este innovador concepto ha sido exitoso en cuanto a sobrevida y función renal aceptable.

En el presente número se incluye interesantes investigaciones sobre peso de un grupo de recién nacidos sanos hijos de mujeres limeñas con embarazos simples sanos, un estudio experimental sobre la administración de sangre de grado y la ausencia de alteraciones bioquímicas hepáticas o renales en animales de experimentación, la satisfacción de usuarios de los servicios de salud, la intoxicación plúmbica crónica en escolares y su asociación con el grado de ansiedad, la incidencia de tuberculosis y virus de inmunodeficiencia humana en las personas de los principales establecimientos penitenciarios del Perú, un recuerdo histórico sobre el fisiólogo británico Joseph Barcroft y su estudio en el Perú sobre las características fisiológicas que permiten a los humanos aclimatarse a la vida en las grandes alturas, y una evaluación sobre la eficacia de un curso en ética médica, explorando los factores que influyen en las decisiones morales y percibiendo los problemas éticos más frecuentes en clínica.

Para finalizar, queremos compartir algunos logros de la revista Anales, la cual está actualmente indizada a Lipecs, Lilacs, Latindex, Red ALyC (Red de Revistas Científicas de América Latina y El Caribe, España y Portugal) y SciELO (Scientific Electronic Library Online, publicación electrónica en Iberoamérica y el Caribe Bireme, Brasil). Debido a ello, es nuestro esfuerzo mantener y mejorar cada vez más su calidad, con especial cuidado en cumplir con las Normas Biomédicas Internacionales (Normas Vancouver). Tenemos referencias autorizadas de que somos considerados como una de las principales revistas médicas del Perú por su periodicidad, tiraje y números al año. Satisfacción que trasladamos a nuestras Autoridades, a quienes escriben para Anales y a Uds., queridos lectores.

\author{
Dr. José Pacheco Romero \\ Anales de la Facultad de Medicina, \\ Universidad Nacional Mayor de San Marcos
}

